\title{
Identification in silico and expression analysis of a $\beta$-1-4-endoglucanase and $\beta$-galactosidase genes related to ripening in guava fruit
}

\author{
Mario A. Mejía-Mendoza' ${ }^{1}$ Cristina Garcidueñas-Piña' ${ }^{1}$ José S. Padilla-Ramírez² ${ }^{2}$ Ruth E. Soria-Guerra ${ }^{3}$ and \\ José Francisco Morales-Domínguez ${ }^{1 *}$ (i)
}

\begin{abstract}
Background: Guava fruit softening is a crucial process during ripening and this process involves a number of enzymes that modifies the cell wall. Two of the enzymes that regulate this process are (a) the $\beta$-1, 4-endoglucanase 17 (BEG) which hydrolyze $\beta-1,4$ bonds from cellulose and hemicellulose, and (b) $\beta$-galactosidase (BGA) that hydrolyzes pectin chains. Bioinformatics and expression analysis information on these genes is limited in guava fruit.

Results: A fragment of a $\beta$-1, 4-endoglucanase 17 (PgE17), and another of a $\beta$-galactosidase (PgGa1) were identified. These sequences have a similarity of more than $85 \%$ with those reported in the NCBI database. In the guava genome, one homologous sequence was found for PgE17 in Chr 4 and two homologous to PgGa1: one in Chr 3 and the other one in Chr 6. Putative protein PgE17 contains part of the glyco_hydro_9 domain. Putative protein PgGa1 has a part of the glyco_hydro_35 domain. Phylogenetic analysis of PgE17 and PgGa1 revealed that both are highly conserved inside the Myrtaceae family. In silico expression analysis showed that both PgE17 and PgGa1 work in a coordinated way with other cell wall modifier enzymes. Expression of these genes was found in all the guava samples analyzed. However, the highest expression was found in the fruit in the breaking and ripe states.

Conclusions: A $\beta$-1, 4-endoglucanase 17, and $\beta$-galactosidase 1 sequences were identified. PgE17 and PgGa1 are expressed in all the plant tissues, and fruit ripening states. Although, the highest expression was on breaker and ripe states.
\end{abstract}

Keywords: Psidium guajava, Cell wall, Expression analysis, Bioinformatic analysis, Cell elongation, Fruit softening

\section{Background}

The guava plant (Psidium guajava L.) belongs to the Myrtaceae family, and it grows on tropical and sub-tropical areas around the globe. Guava fruit has important nutritional properties like the high content of $\mathrm{C}$ vitamin of approximately $80-100 \mathrm{mg}$ per gram of fruit [1]. Also,

\footnotetext{
*Correspondence: francisco.morales@edu.uaa.mx

1 Departamento de Química, Centro de Ciencias Básicas, Universidad Autónoma de Aguascalientes (UAA), Av. Universidad, \#940, Ciudad Universitaria, C.P. 20100, Aguascalientes, Aguascalientes, México

Full list of author information is available at the end of the article
}

it is rich in tannins, tri-terpenes, flavonoids, saponins, lecithin, potassium, and soluble fiber [2]. In México, the guava fruit is one of the most important crops, and the most cultivated cv is the "media china"; which is characterized by its pale pink pulp color, intense sweet flavor, and significant commercial value due to its high demand on food and medicinal products [1]. Recent studies shows that ripening related enzymes and mechanical stresses during post-harvest period alters the cell wall $(\mathrm{CW})$ structure damaging the fruit [3]. 
Due to the climacteric nature of guava fruit, its ripening process is regulated by their breathing levels and ethylene production [4]. Ethylene is the principal autocatalytic hormone in climacteric fruits, it is responsible for synthesizing ripening related enzymes [5]. Most of these enzymes work together in a coordinated way to modify and degrade complex carbohydrates to simple monosaccharides in the CW [6]. This process alters the firmness of the fruit (softening), as well as its flavor, and fosters the generation of volatile organic compounds (odor) [7].

Fruit softening is mainly achieved by the $\mathrm{CW}$ modification, principally in its primary wall pectin and hemicellulose residues [8]. The main enzyme that modify these residues is the $\beta$-1,4-endoglucanase (BEG) (EC 3.2.1.4) which hydrolyze $\beta-1,4$ bonds from cellulose and hemicellulose [9]. This enzyme acts during the breaker and ripe states of ripening when the pectin bonds are stronger, and many cellulose and hemicellulose residues are free. Another $C W$ modifier enzyme is the $\beta$-galactosidase (BGA) (EC 3.2.1.23), which modifies pectin chain structure [10]. This enzyme can be found in three isoforms (I, II, and III), the isoform I is the most related to the ripening process [11]. Its function is to de-ramify pectin chains and the galactans and galactan-pyranoses degradation [10]. Its activity increases during the breaker and ripe ripening periods [12].

In this study, two gene fragments belonging to the $B E G$ (PgE17) and BGA (PgGa1) enzymes in guava fruit were identified and characterized. In addition, the in silico and expression analysis of these two gene fragments in different parts of the guava plant (leaves, stem, and root), and in the green, breaker, ripe, and overripe ripening states of the fruit were performed.

\section{Methods \\ Plant material}

Samples of young leaves, stem, root, and four ripening states of the fruit: green, breaker, ripe, and over ripe (Fig. 1) were analyzed. They were taken from a guava tree c.v. Calvillo S-XX1 [2], located in the Germplasm Bank from the Experimental Site "Los Cañones", belonging to the INIFAP, in the Huanusco municipality, state of Zacatecas, México (latitude 21 ${ }^{\circ} 44^{\prime} 43.6 \mathrm{~N}$; longitude $\left.102^{\circ} 58^{\prime} 02.0 \mathrm{~W}\right)$.

\section{RNA extraction, RT-PCR, and cloning}

Plant material was frozen and powdered with liquid nitrogen, RNA extraction was carried out following the protocol of Doyle and Doyle [13]. cDNA synthesis was performed with the SuperScript ${ }^{\circledR}$ III One-Step RT-PCR with Platinum ${ }^{\circledR}$ Taq kit (ThermoFisher ${ }^{\circledR}$ ). Degenerated oligonucleotides were designed by aligning five different BGA and BEG aminoacidic sequences from taxonomic close plants respectively using the CODEHOP-J program from Viral Bioinformatics Research Center (https://4viro logy.net/virology-ca-tools/j-codehop/) [14]. Aminoacidic sequences from Rhodamnia argentea (XP_030541685.1 and XP_030543190.1), Eucalyptus grandis (XP_010049746.2 and XP_010069895.2), Sysygium oleosum (XP_030443911.1 and XP_030454903.1), Quercus suber (XP_023914075.1 and XP_023907247.1), and Durio zibethinus (XP_022732674.1 and XP_022770876.1), were used to design the oligonucleotides for PgE17 and PgGa1

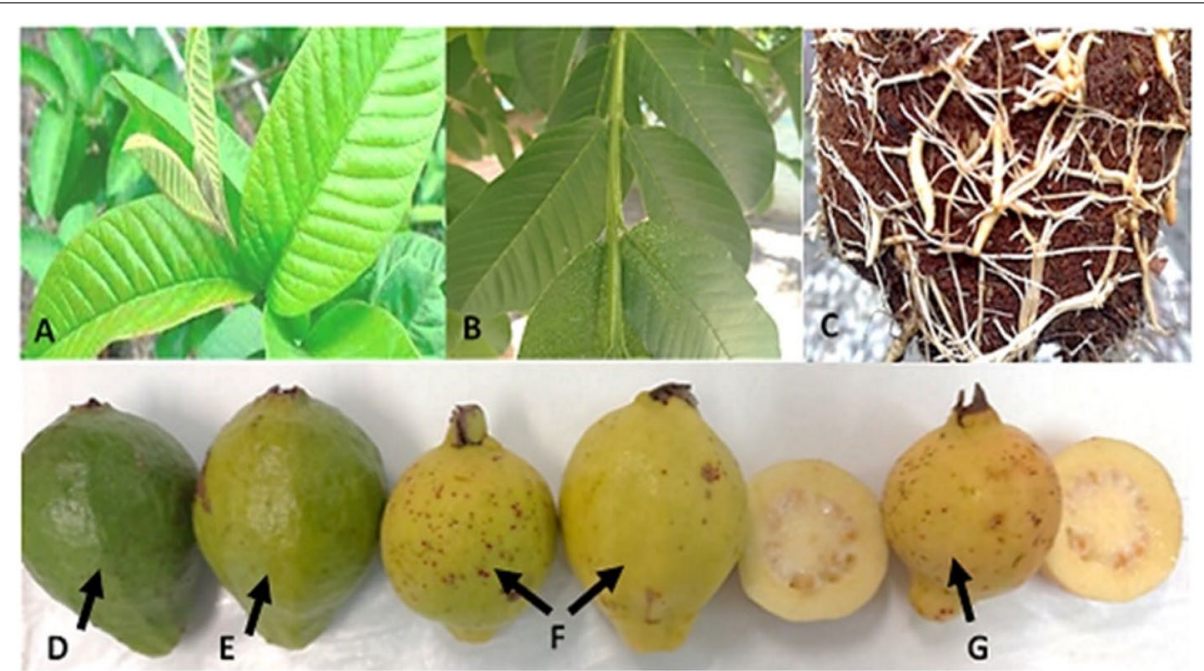

Fig. 1 Sample tissues and ripening states of the guava fruit. A) young green leaves, B) young stem, C) root, D) green state guava fruit; 25 days after floriation, E) breaker state guava; three and a half months after floriation, F) ripe state guava fruits five months after floriation, G) overripe fruit six months after floriation 
(from $B G A$ and $B E G$, respectively). Primers for the $P g E 17$ were forward: 5'-GACAACACCTTCGGCtgggayaa-3', and reverse 5'-GGCCGGCTCGGACTGytcrtartc- ${ }^{\prime}$; and for PgGa1: forward 5'-CAGACCTACGTGTTCtggaaygg- $3^{\prime}$, and reverse 5'-GAAGTTGGTGCCGCCrtgrtacat $-3^{\prime}$. The following PCR programs were used to amplify the fragments: $95^{\circ} \mathrm{C}$ for $10 \mathrm{~min}, 35$ cycles of 95 ${ }^{\circ} \mathrm{C}$ for $1 \mathrm{~min}, 56{ }^{\circ} \mathrm{C}$, (for PgE17) or $52.4{ }^{\circ} \mathrm{C}$ (for PgGa1) for $40 \mathrm{~s}$ and $72{ }^{\circ} \mathrm{C}$ for $90 \mathrm{~s}$, and $72{ }^{\circ} \mathrm{C}$ for $10 \mathrm{~min}$. A PalmCycler $^{\circledR}$ (Corbett Research) thermocycler was used for this process. PCR products were loaded into a $1.5 \%$ agarose gel, stained with ethidium bromide, and visualized under UV light. Wizard ${ }^{\circledR}$ SV Gel and PCR Clean-Up System (Promega ${ }^{\circledR}$ ) and pGEM-T Easy Vector Systems kits were used to purify and cloning the desired PCR products.

\section{Bioinformatic analysis of the sequences}

The obtained sequences were compared with the Eucalyptus grandis genome (Accession number: GCA_016545825.1) and the P. guajava genome assembly guava_V11.23 (Assembly accession number: GCA_016432845.1) [15] in the NCBI database using both nucleotide and aminoacid sequences by the BLASTn, BLASTp and TBLASTN webtools (NCBI, http://www. ncbi.nlm.nih.gov). Virtual translation of putative proteins was made using the Translate tool (https://web. expasy.org/translate/). The isoelectric point, the instability index; the aliphatic index and the GRAVY value of the putative proteins and their homologous regions found in BGA and BEG from $E$. grandis were measured with the ProtParam tool (https://web.expasy.org/protparam/) [16] from the ExPASy website. The CLUSTAL $\Omega$ (https:// www.ebi.ac.uk/Tools/msa/clustalo/) [17] program was used for developing multiple alignments. Phylogeny analysis was performed with the PAUP4 software using: the distance method with DNA/RNA distances uncorrected $\mathrm{p}$, unweighted least squares, negatives branch lengths in zero, all substitutions to the estimate count, output precision for scores up to 5 decimals, and a bootstrap of 100 . Conserved domains and motifs search was performed using PgE17 and PgGa1 as search templates on the pFAM website (https://pfam.xfam.org/) [18]. BGA and BEG from $E$. grandis were used as a biological model for the co-expression analysis in the STRING platform (https:// string-db.org/) [19].

\section{Expression analysis of $\mathrm{PgE17}$ and $\mathrm{PgGa} 1$}

The expression of $P g E 17$ and PgGa1 was analyzed in leaf, stem, and root samples, as well as in fruit in the green, breaker, ripe, and overripe stages of ripening. The ribosomal 25S sub-unit gene from Nicotiana tabacum leaf was used as a reference gene to measure the relative expression as described in other works [20,21]. The green ripening state results were used for data normalization.

The qPCR primers for PgE17 were forward 5'-GGT ACGGTCGTGCTGGTC-3', reverse 5'-GGCGAAGAT CCAGTGCTC-3', and for PgGa1: forward 5'-AAAGGT TCACGCAGAAGATAGT- $3^{\prime}$ and reverse 5'-CTGGTC CAAATTCGTTCTCTAT- $3^{\prime}$. The qPCR reactions were performed using the Applied Biosystems ${ }^{\mathrm{TM}}$ Power SYBR $^{\mathrm{TM}}$ Green PCR Master Mix kit, in a 96-well StepOne ${ }^{\mathrm{TM}}$ RealTime PCR System (Applied Biosystems) thermocycler. Each reaction was assembled as follows: $10 \mu \mathrm{l}$ of Power $\mathrm{SYBR}^{\mathrm{TM}}$ Green PCR Master Mix (2X), 200 ng of cDNA, and $100 \mathrm{nM}$ of forward and reverse primers. The final volume was adjusted to $20 \mu \mathrm{l}$ using Nuclease-Free Water. The PCR conditions were as follows, initial denaturation at $95^{\circ} \mathrm{C}$ for $2 \mathrm{~min}$, followed by 40 cycles of $5 \mathrm{~s}$ denaturation at $95{ }^{\circ} \mathrm{C}$, an annealing and extension cycle at $52{ }^{\circ} \mathrm{C}$ for $30 \mathrm{~s}$. Gathered data was analyzed using the StepOne ${ }^{\mathrm{TM}}$ Real-Time PCR System Software (Applied Biosystems). The relative fold changes in gene expression were calculated by the $2^{-\Delta \Delta c t}$ model.

\section{Results \\ Bioinformatic analysis}

A 331 nt sequence for PgE17 and a putative translation protein sequence of 109 aa were obtained. The blastn and blastp analysis showed $91 \%$ similarity with several sequences reported in the NCBI data bases (Supplementary Figure 1). In E. grandis genome was found three PgE17 homologous genes localized on chromosomes (Chr) 2, 4, and 8 (Supplementary Figure 2) with 89,50 , and $35 \%$ of similarity respectively (Supplementary Table 1). Likewise in the P. guajava genome there are one homologous sequence localized in the Chr 4 (9,959,984 to $9,960,316$ nucleotide; Supplementary Figure 3) with a 98\% identity (Supplementary Table 3 ).

PgE17 aa sequence possesses part of the conserved domain Glyco_hydro_9, also present in the BEG from $E$. grandis and $P$. guajava (Fig. 2). The phylogenetic analysis (Fig. 3) revealed that multiple significative differences exist between the $10 \mathrm{BEG}$ aa sequences from different plants.

For PgGa1, a 750-nt-long sequence and 249 aa for its virtual translation were obtained. The blastn and blastp similitude analysis with BGA aa sequences from other plants showed an average similarity of $95 \%$. With Rhodamnia argentea, Syzygium oleosum, and E. grandis the similarity was $98 \%$, the highest obtained (Supplementary Figure 3). The similarity analysis of PgGa1 (Supplementary Figure 4 ) showed sequences with 71 and $92 \%$ of similitude in Chr 1, 3, 4, 6, 7, and 9 of E. grandis genome. However, a sequence found in the Chr 10 exhibited the 


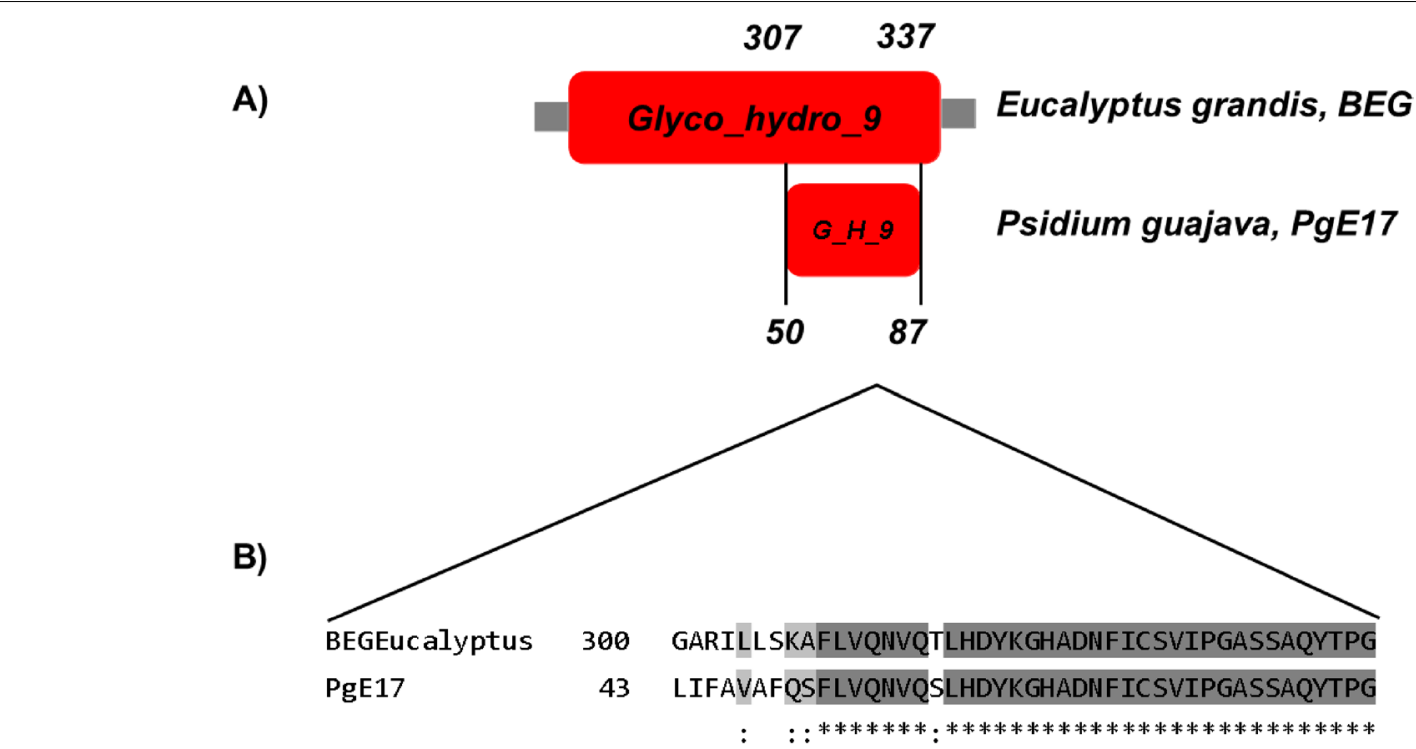

Fig. 2 Graphic representation and alignment of the conserved domain between PgE17 and the BEG from E. grandis. A Glyco_hydro_9 conserved domain from the GH9 family, numbers indicate the position in each amino-acid sequence. B Alignment of the conserved domain. The blue square shows the characteristic PLN02266 domain of the GH9 family

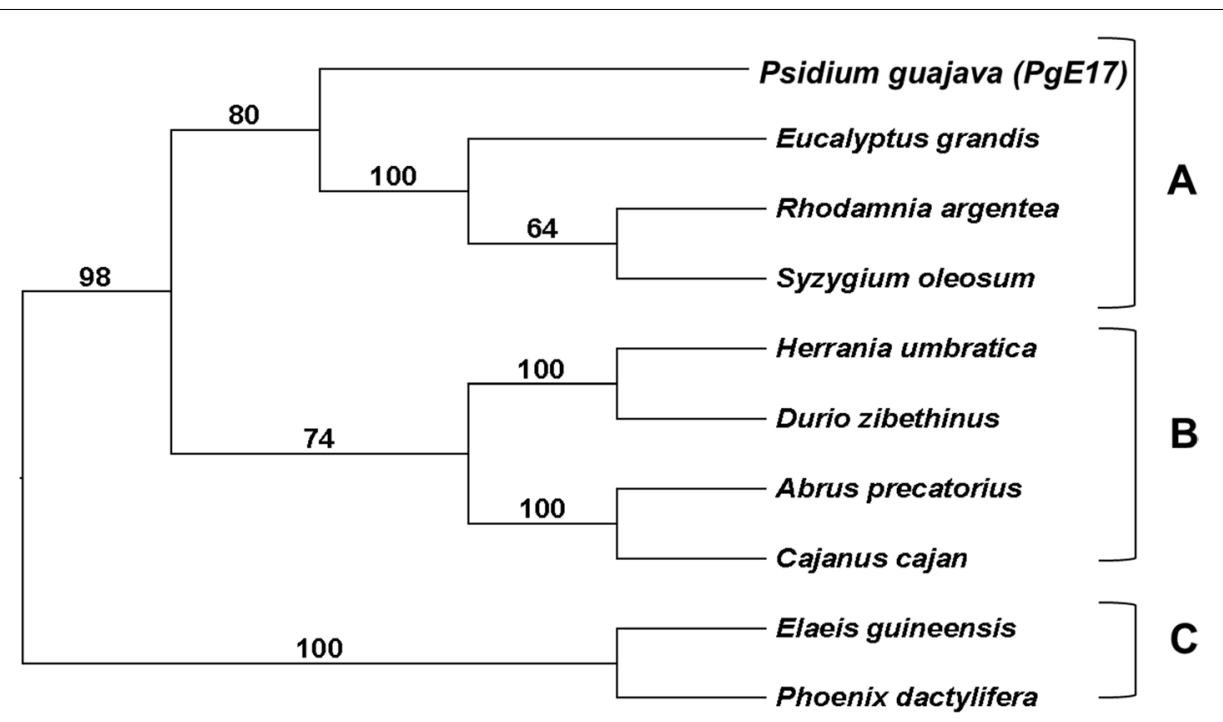

Fig. 3 Distance dendrogram of PgE17 and nine BEG sequences of plants with a bootstrap of 100. Three nodes from different families are shown. A) Myrtaceae family where PgE17 is included. B) Rutaceae and Malvaceae families. C) Fabaceae and Arecaceae families

highest similarity with PgGa1 with 98.2\% (Supplementary Table 2).

Furthermore, PgGa1 blastn analysis on the P. guajava genome founded one identical sequence and one similar sequence on the Chr 6 and 3 respectively (Supplementary Figure 4). Identical sequence found in the Chr 6 is located between the nucleotides $38,077,142$ to $38,077,288$ and has a $100 \%$ identity with PgGa1 (Supplementary Table 4). On the other hand, Chr 3 sequence was from nucleotide 7,575,108 to 7,575,192 and has $83.53 \%$ identity with PgGa1 (Supplementary Table 4).

In the putative aa sequence of PgGa1, the Glyco_ Hydro_35 conserved domain was found, which is exclusive to the BGA and enzymes belonging to the family 35 of glycosyl hydrolases (GH35) [19]. This conserved domain is located between the 29 and 335 aa residue positions in the BGA of E. grandis (Fig. 4). PgGa1 also contains the putative active site GGPIILSQIENEF 

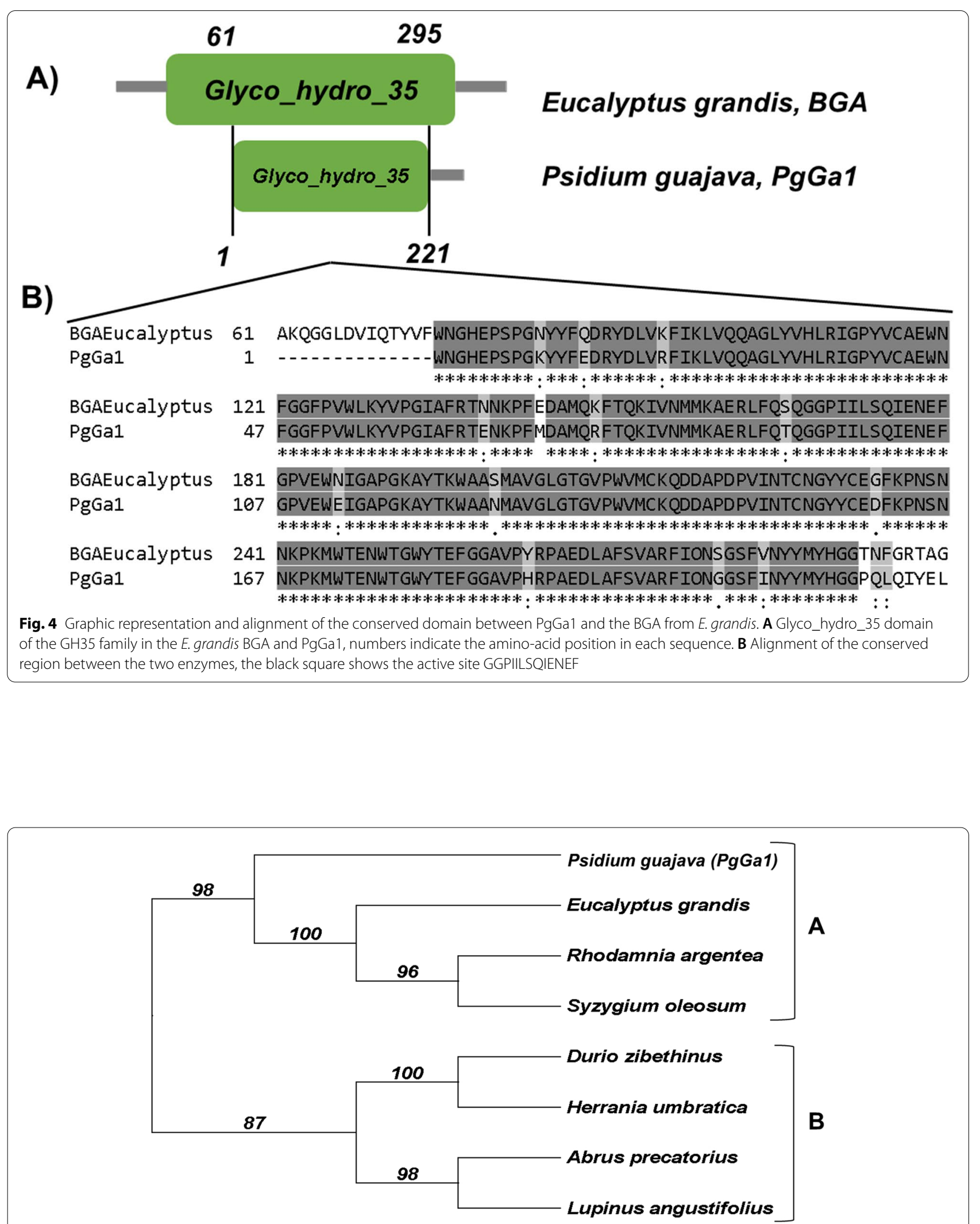

Fig. 5 Distance dendrogram of PgGa1 and ten amino acid sequences of BGA with a bootstrap of 100. Two nodes are shown A) Myrtaceae members only, B) Contains both Malvaceae and Fabaceae members 
Table 1 Parametric values of putative proteins PgE17, PgGa1 from P. guajava, BEG, and BGA from E. grandis and it conserved regions

\begin{tabular}{llllll}
\hline Protein & Theoretical p.I & GRAVY & Aliphatic index & Instability index & Length (aa) \\
\hline B-1,4-endoglucanase 17 conserved region from E. grandis & 7.12 & -0.020 & 86.85 & 17.40 & 108 \\
Conserved region in Chr 4 of P. guajava genome & 6.28 & 0.274 & 94.55 & 37.89 & 101 \\
PgE17 & 6.25 & 0.344 & 96.57 & 40.15 & 108 \\
B-galactosidase 1 conserved region from E. grandis & 5.95 & -0.336 & 62.79 & 33.68 & 247 \\
Conserved region in Chr 6 of P. guajava genome & 6.18 & -0.298 & 65.49 & 31.20 & 204 \\
PgGa1 & 5.54 & -0.476 & 63.16 & 38.72 & 248 \\
\hline
\end{tabular}

pl isoelectric point, GRAVY grand average of hydropathicity

(Fig. 4, black square). The phylogenetic analysis revealed a minimal node formation and situated PgGa1 inside the Myrtaceae family (Fig. 5).

The parametric values showed in Table 1 were used to compare the physicochemical properties of the putative proteins of PgE17 and PgGa1 of P. guajava with the respective $E$. grandis proteins found in the database, both the complete protein and the corresponding conserved region.

\section{In silico co-expression analysis of BGA and BEG}

In silico co-expression analysis of $\mathrm{PgE} 17$ displayed a direct relationship with $\mathrm{CW}$ modifiers proteins and proteins related to the synthesis metabolic pathways of aromatic compounds during the ripening process. $\mathrm{CW}$ modifiers proteins were three expansins, a $\beta$-endo-1,4-manosidase, and a pectinesterase. Besides, the aromatic compounds synthesis related were: a peptide deformylase, a de-phospho-CoA-kinase, a hydroxy-isobutyryl-CoA hydrolase, and a MYB51-like transcription factor (Fig. 6). In silico co-expression analysis for PgGa1 (Fig. 7) showed the association with CW elongation enzymes during ripening such as two xyloglucan endotransglucosylase/hydrolase $(\mathrm{XET} / \mathrm{H})$ and to others that are indirectly related to the ripening process such as the DOMON-domain proteins from the b561 cytochrome, WRKY transcription factor, and a tRNA ligase.

\section{Expression analysis}

qPCR analysis for PgE17 exhibited a higher expression on the breaker state in fruit, equivalent to 50 times more than in the green state. PgE17 expression was between

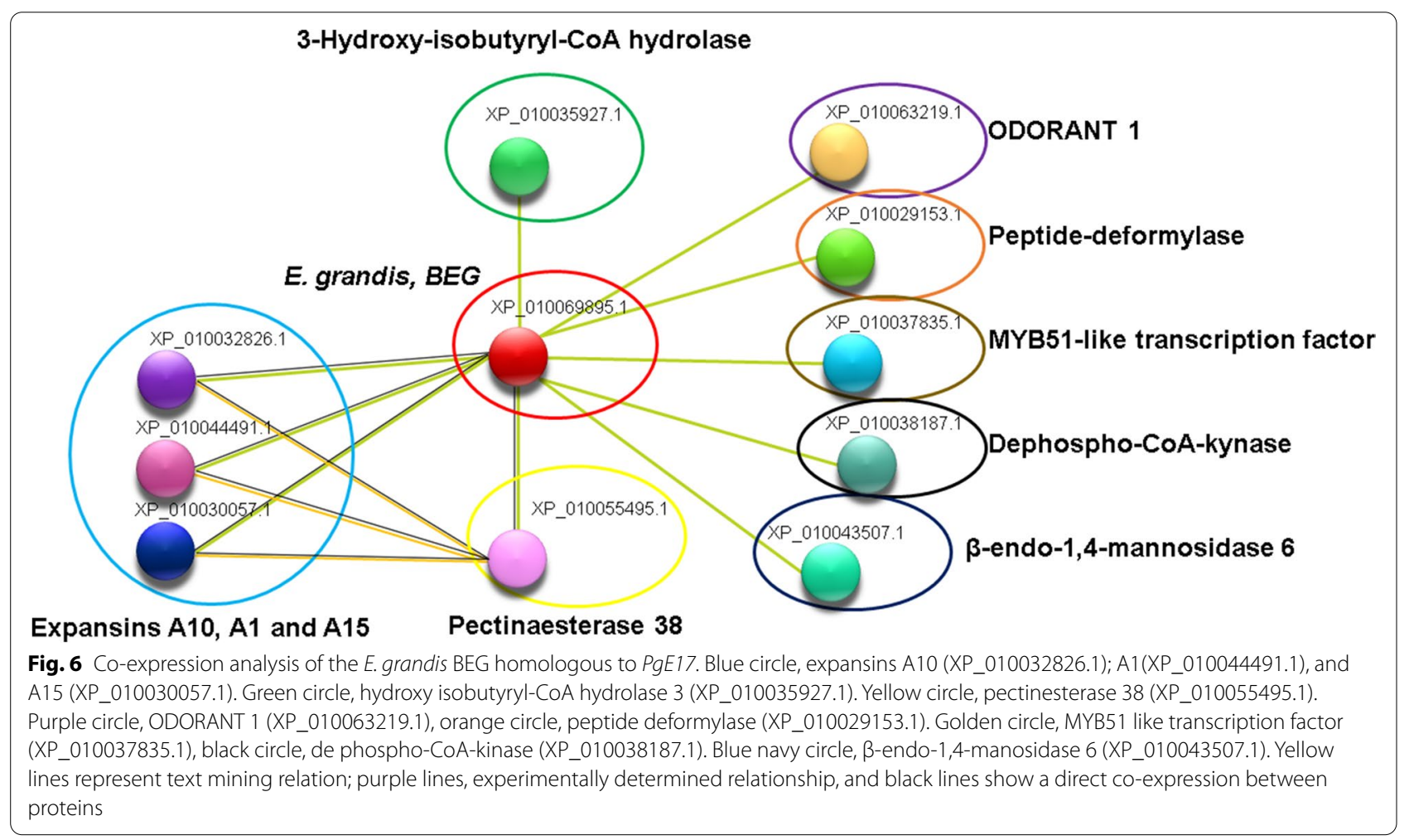




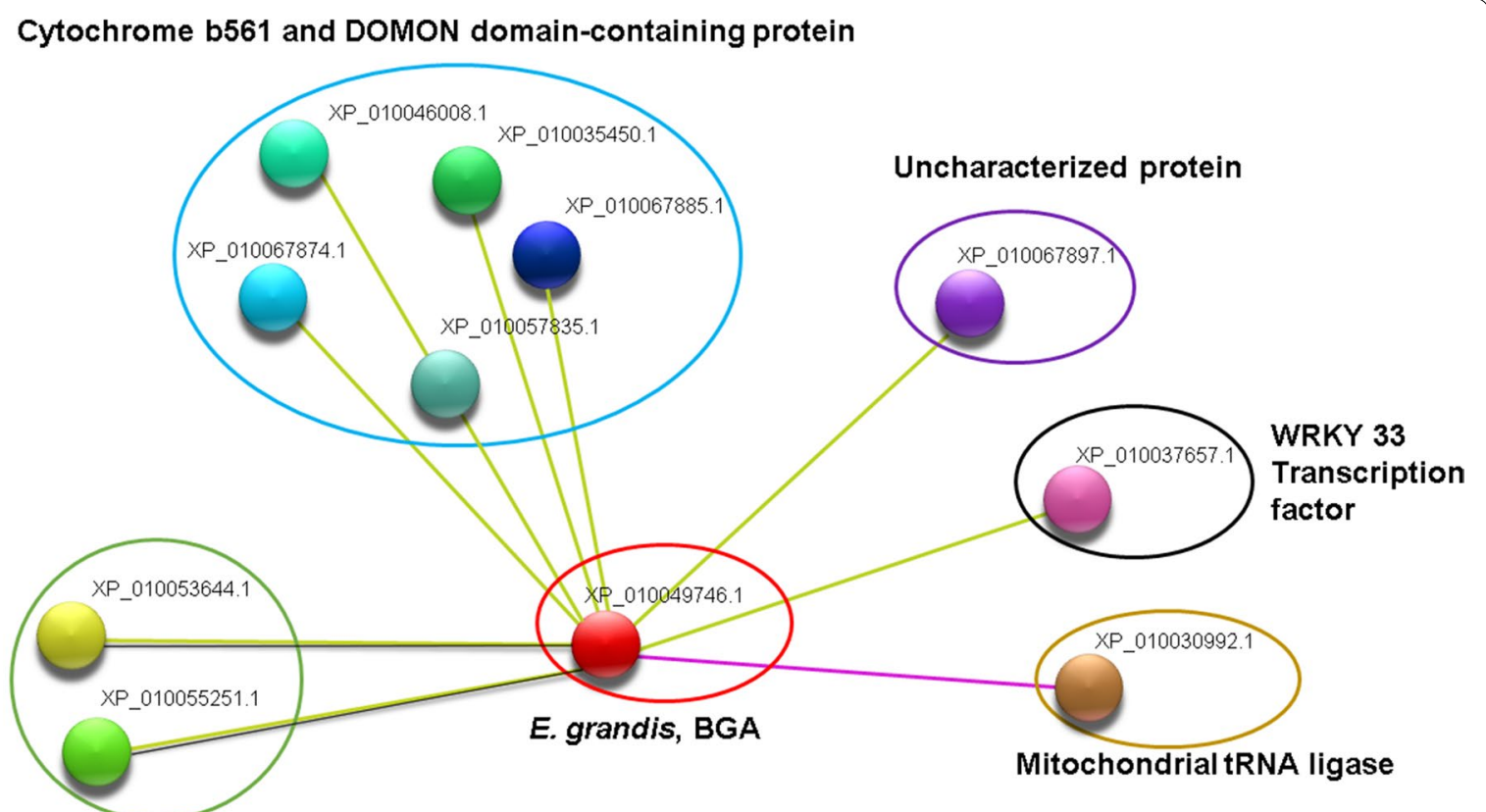

\section{Xyloglucan endotransglucosylase/hydrolase}

Fig. 7 Co-expression analysis of the E. grandis BGA homologous to PgGa1. Blue circle, DOMON domain b561 proteins (XP_010046008.1), b561.2 (XP_010035450.1), b561.3 (XP_010067885.1), b561.4 (XP_010067874.1), and b561.5 (XP_57835.1). Purple circle, uncharacterized protein (XP_010067897.1). Black circle, WRKY 33 transcription factor (XP_010037657.1). Golden circle, tRNA mitochondrial ligase (XP_010030992.1). Green circle, XET/H1 (XP_010053644.1) and XET/H2 (XP_010055251.1). Yellow lines represent text mining relation, purple lines, experimentally determined relationship, and black lines show a direct co-expression between proteins

15 and 20 times lower in ripe and over ripe fruits than breaker fruit (Fig. 8), the expression in the root was the lowest, with about 45 times lower than the breaker. Meanwhile, the expression of PgE17 in stem was 40-45 times higher than the green fruit, being the second higher value. The expression of $B E G$ in leaf was between 18 and 20 more times than in green fruit, the second lowest after root.

For PgGa1 (Fig. 8), the highest expression was found in the breaker and ripe states, with 55 and 45 times more

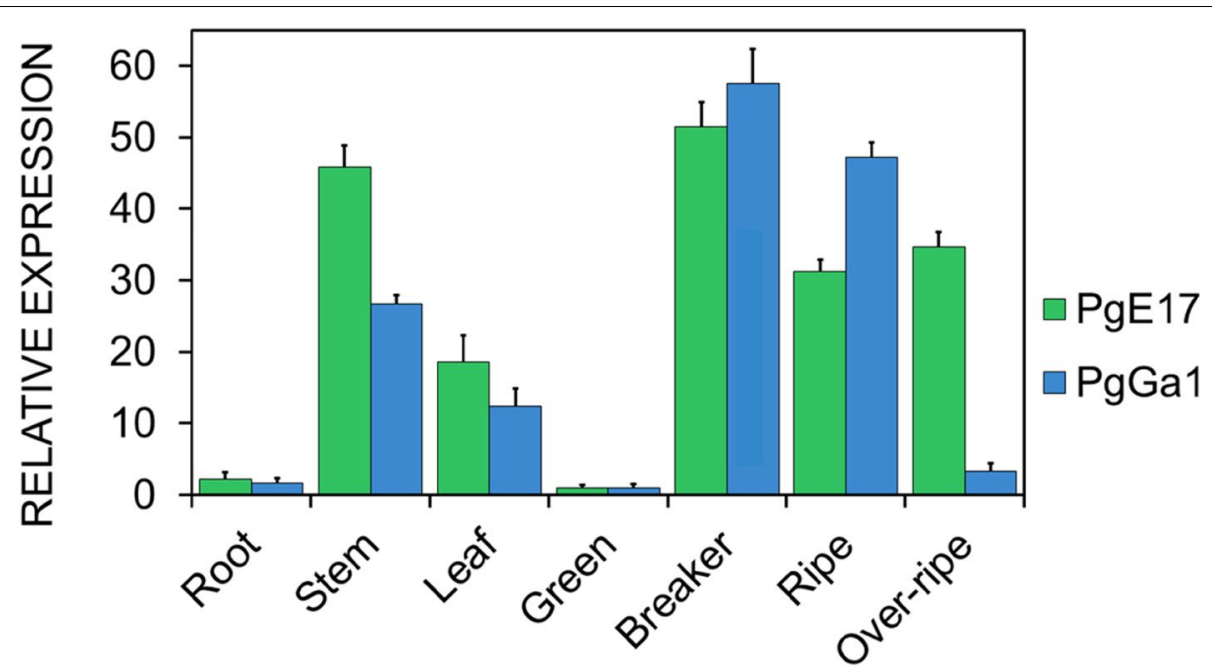

Fig. 8 Expression analysis of PgE17 (green) and PgGal (blue). Expression levels were measured in root, leaves, and stem tissues in four ripening states. The green state was used as a reference for the relative expression 
than in the green state, respectively. On the other hand, $P g G a 1$ expression in the over ripe state was 50 times lower than the ripe fruit. This is the lowest expression of all fruit states, and second lowest of all tissues, only two to three times higher than the expression observed in root. Expression levels in leaves and stem were between 20 to 30 times lower than in fruit, but higher than root; tissue in which expression was null.

\section{Discussion}

Fruit ripening is mainly due to two different metabolic events: starch degradation and cell wall modification [22]. Referring to cell wall compounds, pectin polymers are responsible for the firmness in green fruits and their degradation during the ripening process leads to the softening of the fruit [12]. Like many fruits, guava fruit suffers from these process, several studies have been carried out on the enzymatic activity of both carbohydrate metabolism and the cell wall. The ability to modify the cell wall depends on the type of fruit and in many cases is not related to the softening rate, nor does it depend on the enzymes themselves [22].

There are several works in the literature about the enzymatic activity related to the ripening of the guava fruit, but there are few related to the expression of genes of $B E G$ and $B G A$. Therefore, this work focuses on the identification and bioinformatic analysis and expression study in different organs of the guava plant and its comparison with the enzymatic activity reported in the literature.

The aa sequence of PgE17 contained a conserved region of the Glyco_hydro_9 domain belongs to the family 9 of the glycosylhydrolases (GH9) that modifies the CW indirectly [23], and also contains a high number of contiguous hydrophobic aa that helps shape its tridimensional structure, which is a general characteristic between the BEG enzymes [24].

Physicochemical properties show that PgE17 has different characteristics than the BEG of E. grandis and similar characteristics of the BEG of P. guajava [15]. The $\mathrm{pI}$ value, which is the $\mathrm{pH}$ at which the proteins have no electrical charge, was acidic for PgE17, while it was basic for E. grandis BEG (Table 1). The GRAVY value allows proteins to be classified as hydrophobic, if the value is positive, or as hydrophilic, if the value is negative. Based on the GRAVY values obtained (Table 1), the PgE17 sequence can be considered hydrophobic, like the transmembrane proteins. In contrast, both E. grandis BEG sequences can be considered hydrophilic proteins. The instability index measures the stability of the protein in water, and proteins are considered stable if this index is less than 40. Therefore, the instability index reveal that PgE17 is unstable, while the conserved region of BEG from E. grandis and P. guajava genome are stable
(Table 1). These differences can be attributed to the fact that the aa sequence of the proteins of this family differs from one species to another [23]. The only value consistent across the different sequences was the aliphatic index. This parameter measures the volume occupied by the aliphatic side chains and it is indicative of thermostability, proteins with a high value are stable in a wide temperature range [16]. PgE17, the conserved region of BEG, and the complete BEG protein have large aliphatic index values, revealing their thermostability (Table 1 ). The aliphatic index of PgE17 was higher than that of the conserved region of BEG and that of the full BEG protein from E. grandis (Table 1), indicating that PgE17 is more thermostable.

Phylogenetic differences between 10 BEG from plants including PgE17 were previously described by Jara and Castro [24], which they establish multiple differences between the amino acid sequences in BEG genes inside the GH9 family, which is derived from divergent evolution.

The PgGa1 sequence has similitude with a one sequence of the Chr 10 of $E$. grandis corresponding to BGA and with BGA P. guajava [15]. BGA has been found in Rhodamnia argentea, Syzygium oleosum, and E. grandis, all of them members of the Myrtaceae family. Glyco_hydro_35 domain found in PgGa1 changes the typical configuration of BGA to $\beta$-anomeric [25], allowing the hydrolyzation of the bond between galactose and glucose [26]. On the BGA enzymes active site GGPIILSQIENEF, is located right after the signal peptide, inside the $\mathrm{N}$-terminal region [25] and acts in the p-nitrophenyl$\beta$-D-galactopyranosides and 1,4- $\beta$-D-galactans residues from the CW modifications $[27,28]$.

Parametric analysis showed all sequences analyzed have similar values (Table 1). For example, the negative GRAVY values suggest that are hydrophilic, with a higher probability of being globular. These results, together with the similarity found in the phylogenetic analysis, support the idea that the proteins of this family are conserved in the different species [25].

Low diversification of nodes in the phylogenetic tree indicates that aa sequences of BGA are highly conserved between and inside plant species. A similar phylogeny with a low number of nodes of this protein was described by Smith and Gross [29] and explained by Tanthanuch et al. [25], who mentions that the BGA gene in plants has suffered a minimal number of evolutionary changes since the divergence of plants and animals.

PgE17 co-expressed with several CW modifiers proteins, relates to ripening in the following ways: the expansins hydrolyze the hydrogen bonds from cellulose and hemicellulose, causing the CW expansion [30]; also there is evidence of their high expression on guava fruits 
[31]. The $\beta$-endo-1,4-mannosidase hydrolyze the $\beta-1,4$ intern bonds of mannose chains from the CW producing the characteristically softening during ripening [32]. Pectinesterase 38 de ramify homogalacturonan chains from the $\mathrm{CW}$ releasing hemicellulose and cellulose residues, boosting the softening of the fruit [3]. Peptide deformylase hydrolyses the $\mathrm{N}$-formyl groups from immature protein sequences from chloroplast in plants [33]; malfunction of this enzyme causes the accumulation of misfolded proteins and chlorosis, resulting in bad development and malformation of the plant tissues, including the fruit [34]. The de-phospho-CoA-kinase removes phosphate groups from the phosphorylated CoA groups for the biosynthesis of the A-Coenzyme, which is essential for plant gas exchange during ripening of the fruit [35]. The MYB51-like transcription factor related to the ripening process is significant because it acts as a callose transporter to the CW [36]. Increasing callose concentrations in the CW and phloem have been observed during the ripening of grapefruit (Vitis vinifera) [37]. Regarding aromatic compounds, it has been observed that hydroxyisobutyryl-CoA hydrolase takes part in their synthesis during the ripening of peach fruit (Prunus persica cv. Hujiingmilu) [38]; as well as for the biosynthesis of fat acids [39], which have been related to the ripening of the olive fruit (Olea europea cv. Picual) [40, 41]. The ODORANT1 factor, together with the EOBII transcription factor regulates the production of aromatic compounds in flowers and during the ripening of some fruits like tomato (Solanum lycopersicum), strawberry (Fragaria vesca), and the blueberry (Vaccinium corymbosum) [42].

$P g G a 1$ co-expresses with ripening involved proteins such as, $\mathrm{XET} / \mathrm{H}$ enzymes that induce hydrolysis or addition of xyloglucan chains to the $\mathrm{CW}$, giving extensibility to the cell, which is a necessary process for ripening [43]. Furthermore, PgGa1 is indirectly related to ripening proteins, like those with the DOMON-domain b561, which catalyzes the electrons trans-membranal transport, and the ascorbate regeneration [44]. This could be related to the high amount of $C$ vitamin in the guava fruit [1]. WRKY and RAP2 transcription factors has been observed to act altogether in cellular signaling processes and abiotic and biotic stress responses in guava fruit [45, 46]. High tRNA-met expression levels has been found during the ripening of the palm fruit (Phoenix dactylifera) and tomato [47]. Methionine is the main precursor of ethylene, an essential compound in climacteric fruit ripening [48].

The expression analysis of PgE17 showed a high expression in the breaker period and is could be due because in this state there is an increasing rate of growing and development of the fruit, and the rupture of large amounts of $\beta-1,4$ bonds from hemicellulose is necessary, in which BEG enzymes are involved [49]. Similar results were described by Carey et al., who found high BEG expression levels in tomato fruit in the breaker state [28]. Besides, the decrease in the subsequent states (ripe and over ripe) is caused by the previous accumulation of BEG which caused a depletion of its substrate [50]. This was confirmed in tomato fruit and strawberry by measuring the expression and quantity of BEG enzymes during the breaker, ripe and overripe states, resulting in high concentrations of BEG enzyme during the breaker state and a decrease in its activity in the ripe period $[51,52]$. And the other hand, the low expression of PgE17 in root concords with Buchanan et al. [9], who demonstrated in sorghum (Sorghum bicolor), maize (Zea mays), rice (Oryza sativa), and some pasture (Brachypodium sp.), that BEG expression levels depend on the specie and type of root, among which the root does not need significant modifications on its CW. PgE17 expression in stem and leaves is high due to their constant growth and development rate, BEG enzymes participate in the rearrangement of these structures [50].

In $P g G a 1$ the high expression on breaker and ripe state maybe due to the onset of fruit softening in this period, and so it requires the de ramification of pectin chains that gives support and stiffness to the CW $[3,10]$. These events have been seen in the enzymatic activity of BGA in these states generates a constant amount of hemicellulose residues $[6,53]$, which is related to the high expression of PgE17 found in braker state. This theory is confirmed by Zainon et al. [11], who analyzed the BGA and BEG activity and substrate in mango fruit (Mangifera indica cv. Harumanis), proved that in the breaker and ripe states the decrease in pectin chains caused by BGA enzymes resulted in a reduction of hemicellulose chains due to BEG activity. Significant decrease of $P g G a 1$ expression in the over ripe state is because it is limited to the pectin available chains [10]. The last ripening state exhibits a low quantity of these chains due the action of other enzymes, such as pectinesterases [3] and polygalacturonases [53] that act in response to the massive release of pectin residues caused by BGA. Together, these results indicate that $B G A$ high expression plays a key role in the $C W$ degradation, process which have been stablished as an essential contributor of the softening of the fruit during ripening [15].

The low expression of $B G A$ observed in stem, leaves and roots, suggests that the $\mathrm{CW}$ of these tissues does not need significant modifications. Similar results were reported in apple (Malus domestica) [54]. 


\section{Conclusion}

Two gene partial sequences were identified in the guava plant: $P g E 17$ and $P g G a 1$. Bioinformatic analysis showed that $P g E 17$ belongs to a $B E G$, and $P g G a 1$ to a $B G A$ gene, and that they have homologous in the Myrtaceae family. The $q \mathrm{PCR}$ analysis revealed that the expression of both genes increases in the breaker and ripe stages, which demonstrates the importance of these enzymes in the softening and ripening processes of the fruit.

\begin{abstract}
Abbreviations
CW: Cell wall; BEG: $\beta$-1,4-endoglucanase; BGA: $\beta$-galactosidase; LANBAMA: Laboratorio Nacional de Biotecnología Agrícola y Ambiental; IPICyT: Instituto Potosino de Investigación Científica y Tecnológica; GH9: Family 9 of the glycosylhydrolases; E. grandis: Eucalyptus grandis; GH35: Family 35 of glycosyl hydrolases; XET/H: Xyloglucan endotransglucosylase/hydrolase; tRNAmet: tRNA methionine.
\end{abstract}

\section{Supplementary Information}

The online version contains supplementary material available at https://doi. org/10.1186/s43141-021-00289-x.

\section{Additional file 1.}

\section{Acknowledgements}

The authors gratefully acknowledge the financial support by the Universidad Autónoma de Aguascalientes, under project grant number PIBT17-1, the Consejo Nacional de Ciencia y Tecnología (CONACyT) for the awarded scholarship under the program "Doctorado en Ciencias Biológicas" number 001651, and special thanks to the PhD. Roberto Rico Martínez for taking the time to review this paper. The "Calvillo Siglo XXI" is a local guava variety from Calvillo, Aguascalientes, México that has been registered on the Mexican Catalog for Vegetal Varieties under the register number: GUA-005-160709.

\section{Authors' contributions}

Mejía-Mendoza, Garcidueñas-Piña, Padilla-Ramírez, Soria-Guerra, and MoralesDomínguez have equally contributed to the research work of the current article. All authors have read and approved the manuscript.

\section{Funding}

Financial support was provided by the Autonomous University of Aguascalientes, under project grant number PIBT17-1.

\section{Availability of data and materials}

The datasets generated during and/or analyzed during the current study are not available, only the sequences in the GenBank accessions, but are available from the corresponding author on reasonable request.

\section{Declarations}

Ethics approval and consent to participate

Not applicable.

\section{Consent of publication}

Not applicable.

\section{Competing interests}

The authors declare that they have no competing interests.

\section{Author details}

${ }^{1}$ Departamento de Química, Centro de Ciencias Básicas, Universidad Autónoma de Aguascalientes (UAA), Av. Universidad, \#940, Ciudad Universitaria, C.P. 20100, Aguascalientes, Aguascalientes, México. ${ }^{2}$ Instituto Nacional de Investigaciones Forestales, Agrícolas y Pecuarias. Campo Experimental Pabellón, KM 32.5. Carretera Aguascalientes-Zacatecas, C.P. 20660 Pabellón de Arteaga, Aguascalientes, Ags, México. ${ }^{3}$ Facultad de Ciencias Químicas, Universidad Autónoma de San Luis Potosí (UASLP), Av. Dr. Manuel Nava No. 6-Zona Universitaria, C.P. 78210 San Luis Potosí, S.L.P., México.

Received: 10 June 2021 Accepted: 13 December 2021

Published online: 03 January 2022

References

1. Padilla Ramírez JS, González Gaona E, Rodríguez Moreno VM, Cortés Penagos CJ, Sánchez Rico T (2014) Caracterización morfológica y bioquímica de frutos de guayaba, 1st edn. Sagarpa/Inifap, México

2. Padilla Ramírez JS, González Gaona E, de la Cruz MA P (2010) Nuevas variedades de guayaba (Psidium guajava L.), 1st edn. INIFAP-CIRNOC-Campo Experimental Pabellón, México

3. Cosgrove DJ (2016) Plant cell wall extensibility: Connecting plant cell growth with cell wall structure, mechanics, and the action of wall-modifying enzymes. J Exp Bot 67(2):463-476. https://doi.org/10.1093/jxb/erv511

4. Dolkar D, Bakshi P, Gupta M, Wali V, Kumar R, Hazarika T, Kher D (2017) Biochemical changes in guava (Psidium guajava) fruits during different stages of ripening. Indian J Agric Sci 87:257-260

5. Jain N, Dhawan K, Malhotra SP, Siddiqui S, Singh R (2001) Compositional and enzymatic changes in guava (Psidium guajava L.) fruits during ripening. Acta Physiol Plant 23(3):357-362. https://doi.org/10.1007/ s11738-001-0044-7

6. Franková L, Fry SC (2013) Biochemistry and physiological roles of enzymes that "cut and paste" plant cell-wall polysaccharides. J Exp Bot 64(12):3519-3550. https://doi.org/10.1093/jxb/ert201

7. Rizzo WB (2015) Fatty Aldehyde and Fatty Alcohol Metabolism: Review and Importance for Epidermal Structure and Function. Biochim Biophys Acta 1841(3):377-389. https://doi.org/10.1016/j.bbalip.2013.09.001.Fatty

8. Zhang T, Tang H, Vavylonis D, Cosgrove DJ (2019) Disentangling loosening from softening: insights into primary cell wall structure. Plant J 100(6):1101-1117. https://doi.org/10.1111/tpj.14519

9. Buchanan M, Burton RA, Dhugga KS, Rafalski AJ, Tingey SV, Shirley NJ, Fincher GB (2012) Endo-(1,4)- $\beta$-Glucanase gene families in the grasses: temporal and spatial Co-transcription of orthologous genes. BMC Plant Biol. https://doi.org/10.1186/1471-2229-12-235

10. Nakamura A, Maeda H, Mizuno M, Koshi Y, Nagamatsu Y (2003) $\beta$-Galactosidase and Its Significance in Ripening of "Saijyo" Japanese Persimmon Fruit. Biosci Biotechnol Biochem 67(1):68-76. https://doi.org/ 10.1271/bbb.67.68

11. Zainon MA, Santhi A, Hamid L (1995) B-Galactosidase and Its Significance in Ripening Mango Fruit. Phytochemistry 38(5):1109-1114

12. Braga MA, Marques TR, Simão AA, Botelho LNS, Oliveira LS, Abreu CMP (2018) Mechanism of firmness loss in guava cv. Pedro Sato during ripening at room temperature. Food Sci Technol 38(1):26-32. https://doi.org/ $10.1590 / 1678-457 \times 35416$

13. Doyle JJ, Doyle J (1990) Isolation of Plant DNA from Fresh Tissue. Focus 12(1):13-15

14. Boyce R (2009) iCODEHOP: a new interactive program for designing COnsensus-DEgenerate Hybrid Oligonucleotide Primers from multiply aligned protein sequences. Nucleic Acids Res 37:222-228

15. Feng C, Feng C, Lin X, Liu S, Li Y, Kang M (2021) A chromosome-level genome assembly provides insights into ascorbic acid accumulation and fruit softening in guava (Psidium guajava). Plant Biotechnol J 19(4):717730. https://doi.org/10.1111/pbi.13498

16. Gasteiger E, Hoogland C, Gattiker A, Duvaud S, Wilkins MR, Appel RD, Bairoch A (2005) Protein Identification and Analysis Tools on the ExPASy Server. In: Walker JM (ed) The Proteomics Protocols Handbook. Humana Press

17. Sievers F, Wilm A, Dineen D, Gibson TJ, Karplus K, Li W, Lopez R, McWilliam H, Remmert M, Söding J, Thompson JD, Higgins DG (2011) Fast, scalable generation of high-quality protein multiple sequence alignments using Clustal Omega. Mol Syst Biol 7:539. https://doi.org/10.1038/msb.2011.75

18. Mistry J (2007) Predicting active site residue annotations in the Pfam database. BMC Bioinformatics 8:298. https://doi.org/10.1186/14712105-8-298STRING 
19. Szklarczyk D, Gable AL, Lyon D, Junge A, Wyder S, Huerta-Cepas J, Simonovic M, Doncheva NT, Morris JH, Bork P, Jensen LJ, von Mering C (2019) STRING v1 1: protein-protein association networks with increased coverage, supporting functional discovery in genome-wide experimental datasets. Nucleic Acids Res. https://doi.org/10.1093/nar/gky1131

20. Campos MD, Frederico AM, Nothnagel T, Arnholdt-Schmitt B, Cardoso H (2015) Selection of suitable reference genes for reverse transcription quantitative real-time PCR studies on different experimental systems from carrot (Daucus carota L.). Sci Hortic 186:115-123. https://doi.org/ 10.1016/j.scienta.2014.12.038

21. Iskandar HM, Simpson RS, Casu RE, Bonnett GD, Maclean DJ, Manners JM (2004) Comparison of reference genes for quantitative real-time polymerase chain reaction analysis of gene expression in sugarcane. Plant Mol Biol Report 22:325-337. https://doi.org/10.1007/BF02772676

22. Davies G, Henrissat B (1995) Structures and mechanisms of glycosyl hydrolases. Structure 3(9):853-859. https://doi.org/10.1016/S09692126(01)00220-9

23. Jara K, Castro RI, Ramos P, Parra-Palma C, Valenzuela-Riffo F, MoralesQuintana L (2019) Molecular Insights into FaEG1, a Strawberry Endoglucanase Enzyme Expressed during Strawberry Fruit Ripening. Plants (Basel, Switzerland) 8(6):140. https://doi.org/10.3390/plants8060140

24. Zinin Al, Eneyskaya EV, Shabalin KA, Kulminskaya AA, Shishlyannikov SM, Neustroev KN (2002) 1-O-Acetyl- $\beta$-d-galactopyranose: a novel substrate for the transglycosylation reaction catalyzed by the $\beta$-galactosidase from Penicillium sp. Carbohydr Res 337(7):635-642. https://doi.org/10.1016/S0008-6215(02)00027-7

25. Tanthanuch W, Chantarangsee M, Maneesan J, Ketudat-Cairns J (2008) Genomic and expression analysis of glycosyl hydrolase family 35 genes from rice (Oryza sativa L.). BMC Plant Biol. https://doi.org/10.1186/1471-2229-8-84

26. Juers DH, Matthews BW, Huber RE (2012) LacZ $\beta$-galactosidase: Structure and function of an enzyme of historical and molecular biological importance. Protein Sci 21(12):1792-1807. https://doi.org/10.1002/pro.2165

27. Carey AT, Holt K, Picard S, Wilde R, Tucker CA, Bird CR, Schuch W, Seymour CB, Macrae EA (1995) Tomato Exo-(1->4)-B-D-Galactanase (Isolation, Changes during Ripening in Normal and Mutant Tomato Fruit, and Characterization of a Related cDNA Clone). Plant Physiol 108(3):1099-1107. https://doi.org/10.1104/pp.108.3.1099

28. Smith DL, Gross KC (2000) A family of at least seven $\beta$-galactosidase genes is expressed during tomato fruit development. Plant Physiol 123(3):1173-1183. https://doi.org/10.1104/pp.123.3.1173

29. Fukuda H (2014) Plant cell wall patterning and cell shape. Wiley Blackwell, Japan

30. Reyes-Silva Al, Núñez-Palenius HG, Hernández-Guzmán G, AlpucheSolís AG, Garcidueñas-Piña C, Morales-Domínguez JF (2013) ADNc relacionados con la maduración del fruto de guayaba (Psidium guajava L.): Caracterización y análisis de expresión. Rev Fitotec Mex 36(2):117-125

31. Wang Y, Azhar S, Gandini R, Divne C, Ezcurra I, Aspeborg H (2015) Biochemical characterization of the novel endo- $\beta$-mannanase AtMan5-2 from Arabidopsis thaliana. Plant Sci 241:151-163. https://doi.org/10. 1016/j.plantsci.2015.10.002

32. Hou CX, Dirk LMA, Pattanaik S, Das NC, Maiti IB, Houtz RL, Williams MA (2007) Plant peptide deformylase: A novel selectable marker and herbicide target based on essential co-translational chloroplast protein processing. Plant Biotechnol J 5(2):275-281. https://doi.org/10.1111/j. 1467-7652.2007.00238.x

33. Hou CX, Dirk LMA, Williams MA (2004) Inhibition of peptide deformylase in Nicotiana tabacum leads to decreased D1 protein accumulation, ultimately resulting in a reduction of photosystem II complexes. Am J Bot 91(9):1304-1311. https://doi.org/10.3732/ajb.91.9.1304

34. Shimosaka T, Makarova KS (2019) Identification of Dephospho-Coenzyme A (Dephospho-CoA) Kinase in Thermococcus kodakarensis and Elucidation of the Entire CoA Biosynthesis Pathway in Archaea. Am Soc Microbiol 10(4):1-14. https://doi.org/10.1128/mBio.01146-19

35. Bondada B (2014) Structural and compositional characterization of suppression of uniform ripening in grapevine: A paradoxical ripening disorder of grape berries with no known causative clues. J Am Soc Hortic Sci 139(5):567-581. https://doi.org/10.21273/jashs.139.5.567

36. Bondada B, Harbertson E, Shrestha PM, Keller M (2017) Temporal extension of ripening beyond its physiological limits imposes physical and osmotic challenges perturbing metabolism in grape (Vitis vinifera L.) berries. Sci Hortic 219:135-143. https://doi.org/10.1016/j.scienta.2017.03.002
37. Zhou H, Yu Z, Ye Z, Su M (2018) Multiplex analyses of the changes of aromatic compounds during the development of peach fruit using GC-MS and iTRAQ proteomic techniques. Sci Hortic 236:96-105. https://doi.org/10.1016/j.scienta.2018.03.009

38. Liang Y, Yuan Y, Liu T, Mao W, Zheng Y, Li D (2014) Identification and computational annotation of genes differentially expressed in pulp development of Cocos nucifera L. by suppression subtractive hybridization. BMC Plant Biol 14:205. https://doi.org/10.1186/s12870-014-0205-7

39. Inés C, Parra-Lobato MC, Paredes MA, Labrador J, Gallardo M, SaucedoGarcía M, Gavilanes-Ruiz M, Gómez-Jiménez MC (2018) Sphingolipid distribution, content and gene expression during olive-fruit development and ripening. Front Plant Sci 9:1-14. https://doi.org/10.3389/fpls.2018.00028

40. Parra-Lobato MC, Paredes MA, Labrador J, Saucedo-García M, Gavilanes-Ruiz M, Gómez-Jiménez MC (2017) Localization of sphingolipid enriched plasma membrane regions and long-chain base composition during mature-fruit abscission in olive. Front Plant Sci 8:1-13. https://doi.org/10.3389/fpls.2017.01138

41. Colquhoun TA, Schwieterman ML, Gilbert JL, Jaworski EA, Langer KM, Jones CR, Rushing GV, Hunter TM, Olmstead J, Clark DG, Folta KM (2013) Light modulation of volatile organic compounds from petunia flowers and selects fruits. Postharvest Biol Technol 86:37-44. https:// doi.org/10.1016/.j.postharvbio.2013.06.013

42. Miedes E, Zarra I, Hoson T, Herbers K, Sonnewald U, Lorences EP (2011) Xyloglucan endotransglucosylase and cell wall extensibility. J Plant Physiol 168(3):196-203. https://doi.org/10.1016/j.jplph.2010.06.029

43. Ifigeneia M, Keulemans J, Kanellis A, Davey M (2012) Regulation of fruit ascorbic acid concentrations during ripening in high and low vitamin C tomato cultivars. BMC Plant Biol 12:239. https://doi.org/10.1186/1471-2229-12-239

44. Phukan UJ, Jeena GS, Shukla RK (2016) WRKY transcription factors: Molecular regulation and stress responses in plants. Front Plant Sci. https://doi.org/10.3389/fpls.2016.00760

45. Cheng MN, Huang ZJ, Hua QZ, Shan W, Kuang JF, Lu WJ, Qin YH, Chen JY (2017) The WRKY transcription factor HpWRKY44 regulates CytP450like1 expression in red pitaya fruit (Hylocereus polyrhizus). Hortic Res. https://doi.org/10.1038/hortres.2017.39

46. Marondedze C, Gehring C, Thomas L (2014) Dynamic changes in the date palm fruit proteome during development and ripening. Hortic Res. https://doi.org/10.1038/hortres.2014.39

47. Liu M, Pirrello J, Chervin C, Roustan JP, Bouzayen M (2015) Ethylene control of fruit ripening: Revisiting the complex network of transcriptional regulation. Plant Physiol 169(4):2380-2390. https://doi.org/10.1104/pp.15.01361

48. Levy I, Shani Z, Shoseyov O (2002) Modification of polysaccharides and plant cell wall by endo-1,4- $\beta$-glucanase and cellulose-binding domains. Biomol Eng 19(1):17-30. https://doi.org/10.1016/s1389-0344(02)00007-2

49. Mercado JA, Trainotti L, Jiménez-Bermúdez L, Santiago-Doménech N, Posé S, Donolli R, Barceló M, Casadoro G, Pliego-Alfaro F, Quesada MA (2010) Evaluation of the role of the endo- $\beta$-(1,4)-glucanase gene FaEG3 in strawberry fruit softening. Postharvest Biol Technol 55(1):8-14. https://doi.org/10.1016/j.postharvbio.2009.08.004

50. Llop-Tous I, Domínguez-Puigjaner E, Palomer X, Vendrell M (1999) Characterization of two divergent endo- $\beta$-1,4-glucanase cDNA clones highly expressed in the non-climacteric strawberry fruit. Plant Physiol 119(4):1415-1421. https://doi.org/10.1104/pp.119.4.1415

51. Lashbrook CC, Gonzalez-Bosch C, Bennett AB (1994) Two divergent endo- $\beta-1,4$-glucanase genes exhibit overlapping expression in ripening fruit and abscising flowers. Plant Cell 6(10):1485-1493. https://doi. org/10.1105/tpc.6.10.1485

52. Salazar IA, Gamboa BA (2013) Importancia de las pectinas en la dinámica de la pared celular durante el desarrollo vegetal. Rev Educ Bioquímica 32(2):67-75

53. Yang $H$, Liu J, Dang M, Zhang B, Li H, Meng R, Qu D, Yang Y, Zhao Z (2018) Analysis of $\beta$-galactosidase during fruit development and ripening in two different texture types of apple cultivars. Front Plant Sci. https://doi.org/10.3389/fpls.2018.00539

\section{Publisher's Note}

Springer Nature remains neutral with regard to jurisdictional claims in published maps and institutional affiliations. 